\title{
In the Digital Age, Physical Learning Materials Still Have Their Own Space in Education
}

\author{
Saher F. Ali ${ }^{\mathrm{a}}$ and Mark A. Schier ${ }^{\mathrm{b}}$ \\ Corresponding author: mschier@swin.edu.au \\ ${ }^{a}$ School of Allied Health, Australian Catholic University, Ballarat VIC 3350, Australia \\ bepartment of Health and Medical Sciences, Swinburne University of Technology, Hawthorn VIC 3122, \\ Australia
}

Keywords: Anatomy, Digital learning, Education, Instructional Design, Manuals, Physiology

\begin{abstract}
Swinburne University of Technology (SUT) has a large student cohort undertaking anatomy and physiology as part of their core curriculum. Large student cohorts $(>300)$ impact on the quality and amount of feedback students receive. Teaching and learning materials for students are generally necessary as part of the learning process, and also assist the instructor. This study evaluated whether the introduction of a student laboratory manual enhances student learning and the feedback they receive in the unit of Anatomy and Physiology. It also evaluated the addition of a teaching guide in the teaching experience of tutors in the unit. Anonymous online student and tutor surveys were conducted. Questions regarding the content, presentation and educational value were included in the survey. Students overwhelmingly responded positively to the student laboratory manual. They also believed the amount and quality of feedback received during the unit from their tutor was beneficial to their learning. Students also reported that having a hard copy of their laboratory manual enhanced their learning experience. Therefore, in conclusion the student laboratory manual is a positive introduction into the curriculum of anatomy and physiology. It also identifies potential areas of improvement for the anatomy and physiology curriculum.
\end{abstract}

\section{Introduction}

Teaching materials are generally necessary as part of the learning process (Al Azri \& AlRashdi, 2014; Allwright, 1981), and they also assist the teacher or instructor (Loewenberg-Ball \& Cohen, 1996). Adult learning styles (andragogy) differ significantly from current pedagogical practices as adults create learning connections through the application of teachermade instructional materials, whereas pedagogies are the skills through which children develop new combinations and relationships in organizing ideas, symbols, objects, and words (Charlesworth \& Foster, 1996). Physical learning materials also allow students to record notes on paper that students may refer back to during exam revision. It also allows students to receive real-time feedback from their instructions following the completion of a task e.g. following a laboratory class. Feedback is defined as information about the gap between the actual level and the reference level of a system parameter which is used to alter the gap in some way (Ramaprasad, 1983), hence feedback is a "consequence" of performance (Hattie \& Timperley, 2007) and needs to be easily accessible and individualized for the student. In the context of this paper, feedback could be verbal, written or demonstrative from the laboratory tutor. Formative feedback is critical at university, especially at a first-year undergraduate level as it shapes students' perceptions about tertiary education, continuing academic support and encourages deeper level learning (Biggs, 2003; Weston-Green \& Wallace, 2016). Effective feedback has also been shown to increase student retention during courses and when delivered adequately can be a powerful learning tool that can enhance student learning (Einolander \& Vanharanta, 
2015). Additionally, writing physical notes is acknowledged as enhancing learning (Jabr, 2013; Rivard \& Straw, 2000).

Previously at Swinburne University of Technology (SUT) the unit of Anatomy and Physiology (BIO10004) with approximately an average of 100 students per semester has had a poor retention rate. The practical component has previously consisted of 4 laboratory sessions that were 4 separate electronic documents (fillable pdf forms) that students completed on-line via the Learning Management System (LMS) during their laboratory sessions. Attendance was not compulsory to these sessions. Also, students that did not attend laboratory sessions had the opportunity to submit their work on-line. Due to an online submission alternative, attendance to laboratory sessions was low and students would usually submit their work electronically mostly by copying from their peers. The submission of work was usually reporting observations of the activities with no follow-on questions. We have not reported on student grades, as we were focussed initially on improving the educational practice.

Due to poor attendance and lack of structure of the practicals students did not get to see any application of the physiological content, neither were students able to translate all their theoretical knowledge into a practical context and would not have the opportunity to ask content related questions that students would ask academics outside lectures. It also prevented students from receiving feedback regarding their progress in the unit that usually occurs during small sized laboratory sessions (approx. 20-30 students per session). Also, with rapid expansion of the unit from 100 to nearly 500 students enrolled from semester 1, 2018 onwards, it is necessary that the teachings of the unit are consistent amongst all students and tutors to ensure that the delivery of the unit is streamlined across all aspects of the unit. We also wanted to collect some student perceptions of their learning overall, as these are related to their overall performance (McVicar et al., 2015).

Large student cohorts have an impact on the quality and amount of feedback students receive throughout the semester and can also hinder the learning experience, hence teaching and learning materials for students which are regularly checked are a necessary part of the learning process of an important unit such as anatomy and physiology. Teaching and learning materials for students. are an integral part of the learning process, and assist the instructor (Singer \& Alexander, 2017) to ensure that teaching is streamlined amongst all teachers. In corporate environments, manuals and handbooks serve as useful documents where both employers and employees can refer to for certain subject matters regularly. There has been interest in the efficacy of digital learning materials in comparison to their traditional hard copy counterpart. Studies have found in the age of digital natives, students still appreciate learning using physical materials (McLaren, 2008). Some studies contrast the use of screen and papers/textbooks (Chen, \& Catrambone 2015), with guarded preference for the paper-based until there is a marked improvement in the quality of e-readers (Myrberg \& Wiber, 2015). The use of paper (or permanent pdf documents) also promotes the keeping of permanent records as good laboratory practice (Schreier et al., 2006). Because of low participation rate in the unit when the practical assessment component was available online via the LMS, the aim of this study was to evaluate whether the introduction of a physical student laboratory manual and tutor guide enhances both student learning and the feedback they receive in the unit of Anatomy and Physiology at Swinburne University of Technology. 


\section{Methods}

At SUT, attendance to laboratory sessions is not compulsory. This was reflected in the unit learning objects that were articulated;

1. Locate and identify anatomical structures in the human body

2. Differentiate between levels of organization in biological systems and apply this knowledge to anatomical and physiological concepts.

3. Explain the functions of organs and organ systems and their roles in normal bodily function.

4. Differentiate between normal and abnormal physiology

Due to the non-compulsory attendance of the unit, we were presented with the problem on how to motivate students to attend. Hence, a complete overhaul of the practical component of the curriculum was done. A laboratory manual was written that was a coherent document that contained all of the practical sessions that were being conducted. The document was printed in colour and sold in the university bookshop for a minimal cost. The document outlined student expectations for the unit, as well as advice on how to excel in the unit. All of the practical sessions were rewritten to ensure that activities could be completed within a maximum period of 1 hour and 45 minutes, allowing sufficient time (15 minutes maximum) for tutors to provide meaningful feedback to students within the 2-hour session. The document also contained space for students to take extra notes and for tutors to give feedback. All of the activities that were designed had associated questions (refer to Figure 1).

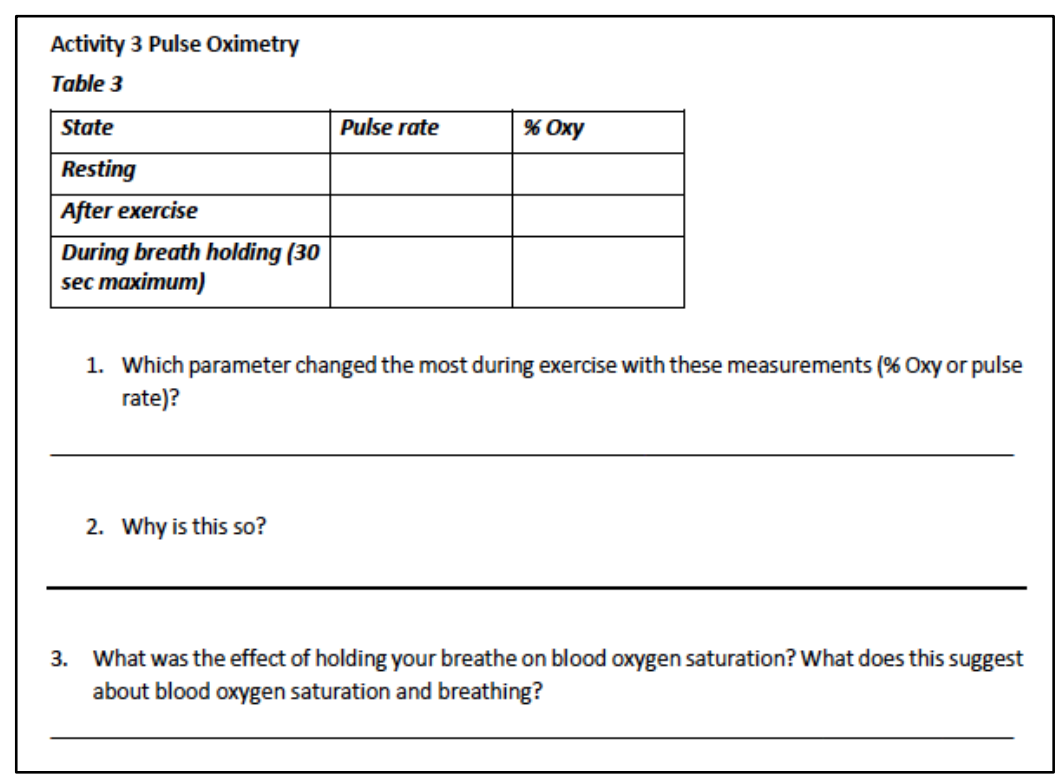

Figure 1: Sample activity from student laboratory manual (activity + questions).

To overcome the obstacle of attendance, the practical component was made $20 \%$ of their summative assessment ( 4 x 5\% each). Students were not allocated 5 marks for attending; rather marks were allocated based on attempting the activities and attempting the associated questions. To ensure students have a basic understanding of the theory that is being applied during the practical session, pre-lab activities were set with each practical session that were discussed and checked before the laboratory session and also contributed to the final mark. Alongside the student laboratory manual, a tutor guide was also designed that clearly 
articulated expected learning outcomes and teaching and learning expectations. It also contained troubleshooting and solutions to all the questions relating to the practical session that tutors could refer to when checking students' work or when unclear on certain concepts.

The students would complete the set activities with assistance from the tutors when needed. Upon completion of the activities the manual was individually checked at the end of each session and a mark (out of 5) was allocated. Tutors were instructed not to simply check their work but also provide written and verbal feedback to increase students' understanding of the relevant physiological concepts. Students were not provided with an alternative online submission during the semester to deter student absence. Students who were not able to attend their designated laboratory session were given the opportunity to attend another session during the week to prevent them from "losing" their mark.

Human Experimental Ethics approval was obtained from the SUT Human Research Ethics Committee. Anonymous online student and tutor surveys were conducted. Both documents (student laboratory manual and tutor guide) were updated to reflect any changes that occurred in the unit at the end of each teaching semester.

Students were surveyed on their experience of the laboratory manual using an online survey tool, Opinio (http://www.objectplanet.com/opinio/). The following themes were put forward to students:

1. Organisation and Presentation

2. Content and Educational value

3. Feedback received

4. Hard copy vs soft copy

All questions were answered using a Likert scale (e.g. strongly agree to strongly disagree) for both students and tutors. An opportunity to provide further comments was provided at the end of the survey in the form of "Do you have any other further comments?" Results were collected and analysed.

Of the 500 students only 40 responded (a small rate of around 8\%) and of the 6 tutors 4 responded. The data presented in this paper are representative from the first student cohort to have completed the practical component using the student laboratory manual.

\section{Analyses}

All results are expressed on a bar graph, where $n$ represents the number of respondents for each question. The results represent responses accumulated from the 2018, semester 1 iteration of the unit. Graphpad Prism version 8.0 (Graphpad Software, San Diego, CA, USA) was used for presentation of the data.

\section{Results}

\section{Organisation and Presentation}

Greater than $50 \%$ of the respondents agreed that a well-presented single document which contains their practical curriculum and outlines expectations of the student and unit allows them to stay organised throughout the semester (refer to Figure 2). Although the opinion on the general presentation of the laboratory manual was divided, there were no comments provided in the open-ended section that could provide insight into the divergent opinions. It also assisted their learning of anatomy and physiology. One student's opinion was that: 
"It was very helpful through the semester."

a) How would you rate the general presentation of the manual?

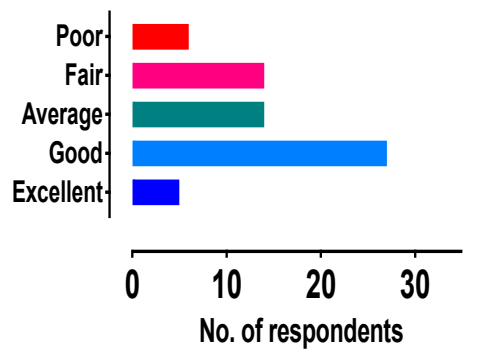

b) The student laboratory manual clearly outlines my expectations for the unit?

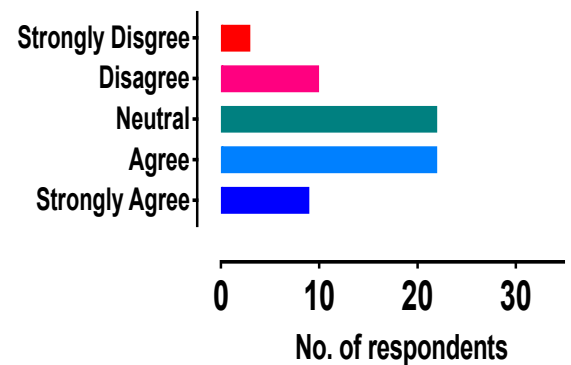

c) The student laboratory manual has kept me organised throughout the semester?

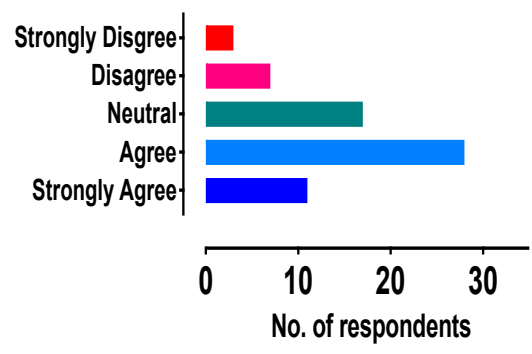

Figure 2: Organisation and Presentation.

\section{Content and Educational value}

Most respondents found the student laboratory to have high educational value and it enhanced their anatomy and physiology learning experience (refer to Figure 3). Compulsory pre-lab activities that required completion before coming to class were also agreed to have a strong educational value, and one student commented:

"The manual itself has aided the learning of many students during the semester. It would be very handy if the manual was mentioned or referred to more during the lectures"

a) How would you rate the educational value of the student laboratory manual?

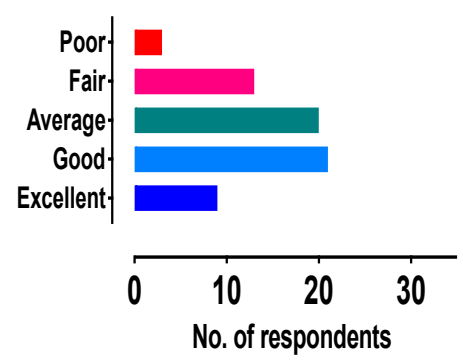

b) The student laboratory manual has assisted my learning of anatomy and physiology?

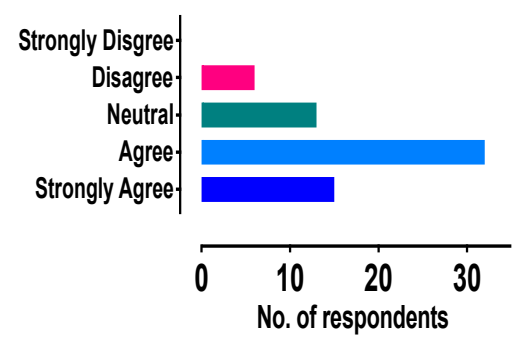

c) Having pre-lab activities improves my knowledge and preparation for the laboratory session

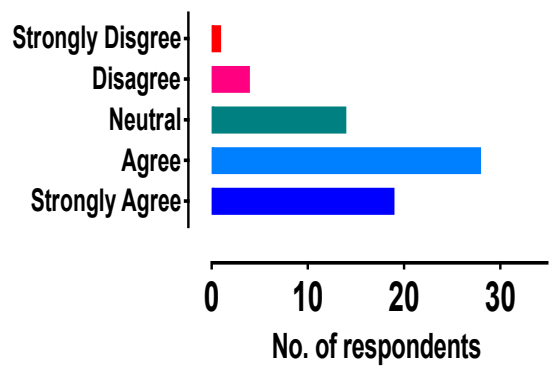

Figure 3: Content and educational value.

\section{Feedback received}

Greater than $70 \%$ of respondents did receive formal feedback from their tutors during the laboratory sessions that subsequently had a positive impact on their learning experience (refer to Figure 4). A comment from one student was:

“...I also got useful feedback from the tutors on any answers I may have gotten." 
a) I recieved formal feedback from my tutors when they were reviewing my logbook during the laboratory sessions?

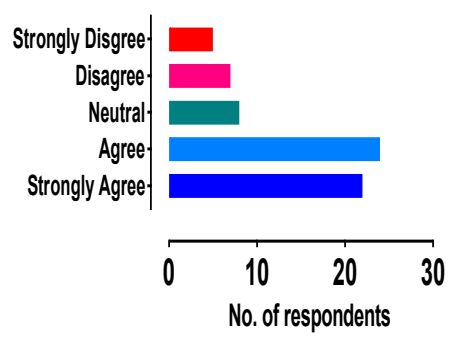

b) The feedback recieved from my tutors when reviewing my logbook has increased my understanding of anatomical and physiological concepts I learnt during the lecture series.

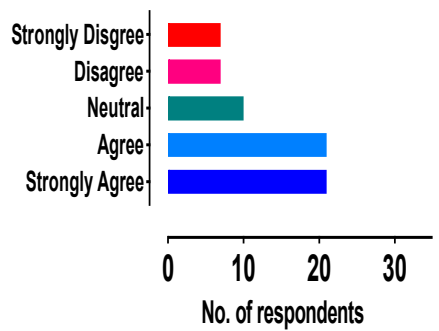

c) I would use the student laboratory manual for the end of semester examination?

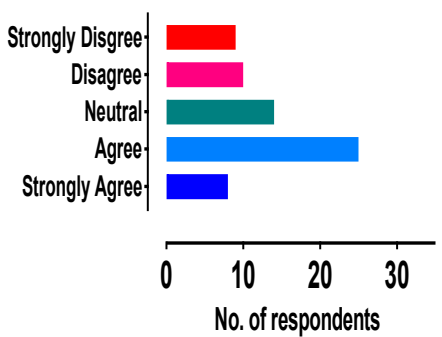

\section{Figure 4: Feedback}

\section{Benefits of Hard copy.}

Most students also felt that having a hard colour copy of the document in comparison to an electronic version of the manual was beneficial to their learning of anatomy and physiology (refer to Figure 5). Comments from the students included.

"I really think this was helpful. If it was online and didn't involve a prelab I wouldn't have looked at anything before the lab and been prepared for it, but having a hardcopy meant I read everything on the train before coming to the lab - enhancing my learning."

"Good having a physical copy, having to buy it is a bit of a pain but it was cheap so not too bad. Having a bit more space to writelpaste pictures in would be good.

a) Having a hard copy of the student manual enhances my learning experience of anatomy and physiology

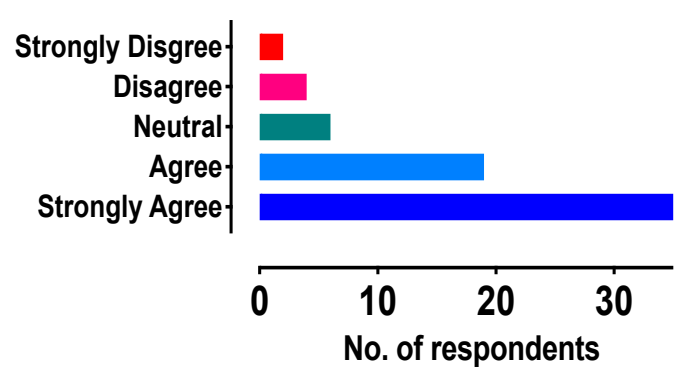

b) If the manual was uploaded into Blackboard/Canvas how likely would you be to print the document in colour?

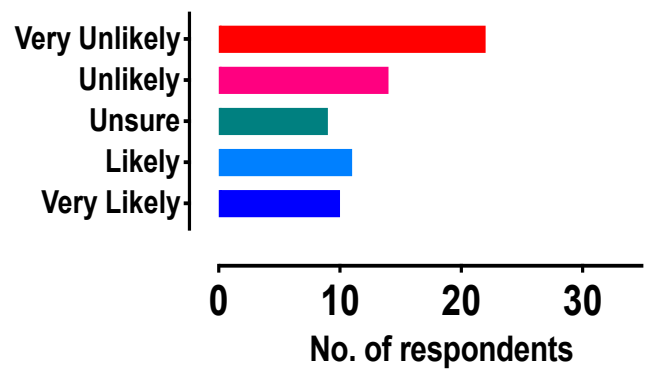

\section{Figure 5: Hard copy vs soft copy}

\section{Tutor responses}

Both the student laboratory manual and tutor guide have had a positive reception from the tutors (refer to Figure 6). It is a well-presented document and it has increased the consistency in the delivery of the anatomy and physiology curriculum and has increased the efficiency of the tutors at being able to deliver the practical component of the unit (refer to Figures 5C\&D). Having clear expectations and defined learning outcomes for each laboratory session assists tutors in teaching anatomy and physiology who may not have a strong grasp of certain concepts (refer to Figures 5A, E\&F). 
a) The tutor guide clearly outlines my teaching expectations for the unit?

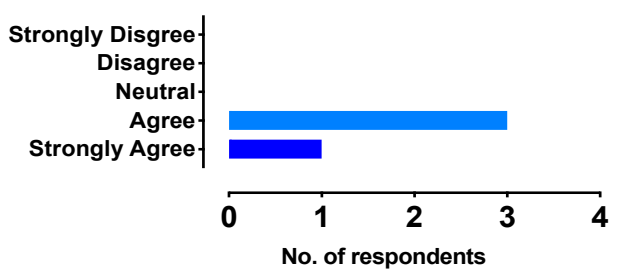

c) The laboratory sessions run with more ease with the introduction of a tutor guide

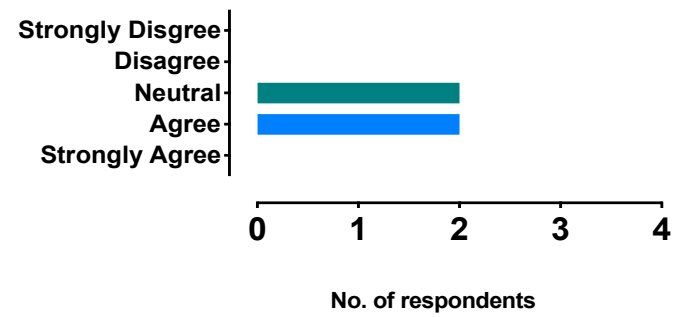

e) The information provided in the student laboratory manual has assisted me teaching anatomy and physiology?

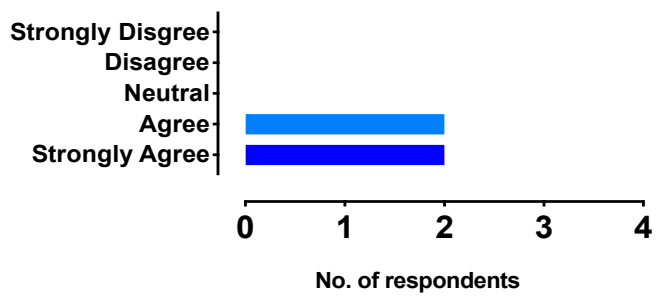

b) How would you rate the general presentation of the student

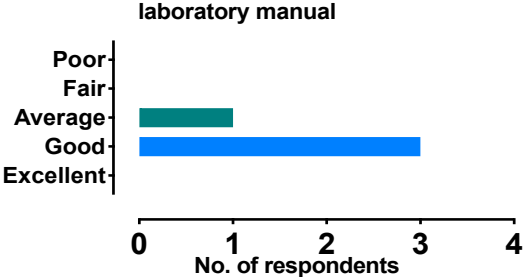

d) The laboratory sessions run with more ease with the introduction of a student laboratory manual

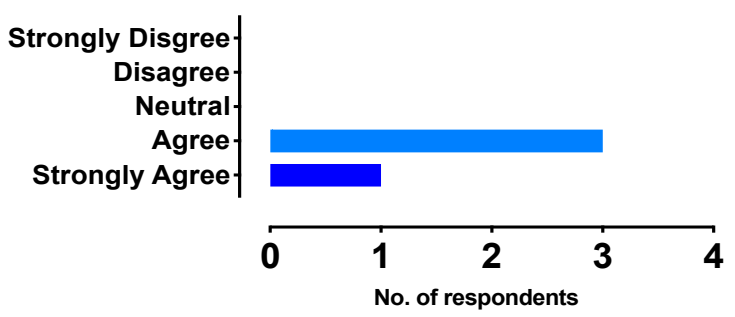

f) The information provided in the tutor guide has assisted me teaching anatomy and physiology

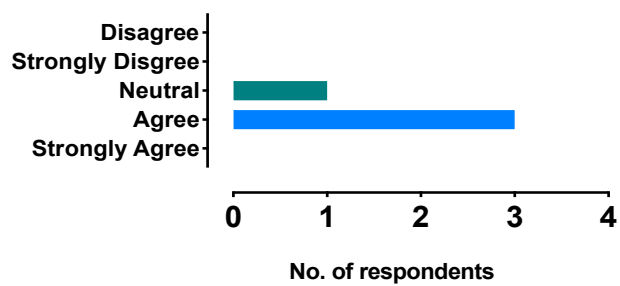

\section{Figure 6: Tutor responses}

\section{Discussion and Conclusion}

This study has demonstrated that despite an increase in the shift of learning to a digital first environment, physical learning materials such as student manuals serve as a useful learning tool. This study also provides insight into how the student laboratory manual has also acted as a powerful tool in providing feedback. Greater than $70 \%$ of the surveyed students found the student laboratory manual was a well-presented document that clearly outline student expectations throughout the semester (refer to Figure 2). However, these observations are based on a small overall response rate. They also believed that the document had high educational value and it enhanced their anatomy and physiology learning experience (refer to Figure 3 ). Having well-presented and coherent learning materials sets a precedence for a unit where the needs of the learner are at the forefront. By outlining expectations and guidance for students about the unit was also viewed as a positive addition which provided students with a single "go to document" which students can refer to time and time again and take additional notes through the semester.

The finding that the study demonstrates that the majority of responding students received formal feedback from their tutors during the laboratory sessions and had a positive impact on their learning experience (refer to Figure 4) is a validation of our aims. Feedback is an interesting phenomenon as there are 2 components of it. The perception of which behaviours 
and attitudes students perceive as feedback and the instructors view of how feedback is being given e.g. through verbal or written comments, content revision, etc. (Weaver, 2007). Hence, one successful definition of student feedback can be interpreted as when feedback is delivered from an instructor with the intention to enhance student learning is received with the same intention. If feedback is not noticed or is not interpreted as feedback the purpose of the whole activity can prove to be futile. This study demonstrated that students positively responded to the verbal and written feedback that they received, which was reflected in their overall results and unit student feedback. Following each laboratory session, students were able to gain a better understanding of the anatomical and physiological concepts that were presented to them (refer to Figure 4). In addition, because the feedback is delivered regularly throughout the semester, it establishes rapport between the student and faculty. While we have not been able to align this with changes in student grades, it is better educational practice. This is also a part of the principles of good practice in undergraduate education (Chickering \& Gamson, 1987). Also, having this strong foundation in first year concepts is necessary for all first-year degrees as it will allow students to build a strong understanding in their undergraduate degree, and translation and application of difficult concepts.

Our student survey finally examined whether the students found a hard copy of the document a useful component of the curriculum in comparison to it previous digital predecessor. Due to the student laboratory manual containing many anatomical figures, we decided that the document will be printed in colour to control the quality of the image reproduction. It is reasonable to assume that not all students would print this in colour if uploaded to the LMS due to cost considerations. In that case, the educational value of the figures will be lost as a result. In retrospect this was a good decision as many of the students were highly unlikely to print the document in colour (refer to Figure 5). By printing in mass, with economies of scale, the university was able to deliver high quality document at a minimal cost and provide an engaging learning document with high educational value. The students also agreed that having a hard copy of the document was beneficial to their learning and they would use the manual to revise for their end of semester examination. There have been many studies comparing the difference between digital learning vs "print" learning. A study conducted by Mangen and colleagues in 2012 compared reading comprehension in Year 10 students who read from paper and the same text (pdf document) from a computer screen. The study found that students who read from the printed text scored significantly better than the ones who read the text digitally (Mangen, Walgermo, \& Bronnick, 2012). A similar result was found at a tertiary level where a study conducted by Mirzachi in 2015 revealed that at the University of California, Los Angeles students preferred print textbooks over digital textbooks and electronic documents such as .pdf's during their learning (Mirzachi, 2015). Printed texts provide a tactile environment where the brain can treat words like objects. When we read, our brains construct a mental representation of the text. This is very similar to mental maps that we create of physical spaces, such as housing and office floor plans. This phenomenon can be well demonstrated in published studies, people report that when trying to locate a particular passage in a text, the location of the text e.g. the page number or physical location of the page is where the text appears is remembered (Jabr, 2013). Hence, it can be suggested that a printed text in combination with regular documented feedback serves a powerful learning tool.

The responses of the tutors when compared to the student responses formed the final component of the study. The tutors shared similar sentiments where the introduction of the student laboratory manual and the teaching guide had a positive reception. They also indicated the laboratory sessions were running with more ease when both students and tutor expectations are clearly articulated. Tutors also believed that the tutor guide assisted their teaching of 
anatomy and physiology. An interesting theme that was revealed from the unit feedback (not part of data) was that students specifically mentioned how much they enjoyed the laboratory sessions and that they requested the introduction of extra laboratory sessions (greater than 4). This recommendation was put forward to the department, which resulted in an increase in the number of laboratory sessions from 4 to 6 per semester during the 2019 iteration of the unit.

Therefore, in conclusion, this study has demonstrated that when a well written (preferably colour) printed learning manual, in conjunction with regular feedback, is provided to the student is a highly useful learning material in the anatomy and physiology curriculum. Also, more consistent delivery makes teaching delivery consistent across a large cohort using more than one staff member.

\section{Acknowledgements}

Laboratory tutors and colleagues for feedback on revisions of the student and tutor guides.

\section{References}

Al Azri, R. H., \& Al-Rashdi, M. H. (2014). The effect of using authentic materials in teaching. International Journal of Scientific \& Technology Research, 3(10).

Allwright, R. L. (1981). What do we want teaching materials for? ELT Journal, 36(1), 5-18.

Biggs, J. (2003). Teaching for quality learning at university (Second Edition ed.). England: University Press.

Charlesworth, S. M., \& Foster, I. D. L. (1996). 'Water and environmental systems': achieving student-centred learning objectives with an undergraduate journal. Journal of Geography in Higher Education, 20(1), 45-54.

Chen, D.-W., \& Catrambone, R. (2015). Paper vs. Screen: Effects on Reading Comprehension, Metacognition, and Reader Behavior. Proceedings of the Human Factors and Ergonomics Society Annual Meeting, 59(1), 332-336. https://doi.org/10.1177/1541931215591069

Chickering, A. W., \& Gamson, Z. F. (1987). Seven Principles for good practice in undergraduate education. American Association for Health Education Journal, 3, 3-7.

Einolander, J., \& Vanharanta, H. (2015). Assessment of student retention using the Evolute approach, an overview. Procedia Manufacturing, 3, 581-586.

Hattie, J., \& Timperley, H. (2007). The power of feedback. Review of Educational Research, 77(1), 81-112.

Jabr, F. (2013). Why the brains prefer paper. Scientific American, 48-53.

Loewenberg-Ball, D., \& Cohen, D. K. (1996). Reform by the Book: What Is — or Might Be — the Role of Curriculum Materials in Teacher Learning and Instructional Reform? Educational Researcher, 25(9), 6-8.

Mangen, A., Walgermo, B. R., \& Bronnick, K. (2012). Reading linear texts on paper versus computer screen: Effects on reading comprehension. International Journal of Educational, 58, 61-68.

McLaren, S. V. (2008). Exploring perceptions and attitudes towards teaching and learning manual technical drawing in a digital age. International Journal ofTechnology and Design Education, 18(2), 167-188.

McVicar A, Andrew S, Kemble R. The ‘bioscience problem' for nursing students: an integrative review of published evaluations of Year 1 bioscience, and proposed directions for curriculum development. Nurse Educ Today 35: 500-509, 2015. doi:10.1016/j.nedt.2014.11.003

Mirzachi, D. (2015). Undergraduates' academic reading format Preferences and behaviors. The Journal of Academic Librarianship, 41(3), 301-311.

Myrberg, C., \& Wiberg, N. (2015). Screen vs. paper: what is the difference for reading and learning?. Insights, 28(2), 49-54. DOI: http://doi.org/10.1629/uksg.236

Ramaprasad, A. (1983). On the definition of feedback. Behavioral Science, 28, 4-13.

Rivard, L. P., \& Straw, S. B. (2000). The effect of talk and writing on learning science: An exploratory study. Science Education, 84(5), 566-593.

Schreier, A. A., Wilson, K., \& Resnik, D. (2006). Academic research record-keeping: best practices for individuals, group leaders, and institutions. Academic medicine : journal of the Association of American Medical Colleges, 81(1), 42-47. doi:10.1097/00001888-200601000-00010

Singer, L. M., \& Alexander, P. A. (2017). Reading across mediums: Effects of reading digital and print texts on comprehension and calibration. The Journal of Experimental Education, 85(1), 155-172. doi:10.1080/00220973.2016.1143794

Weaver, M. R. (2007). Do students value feedback? Student perceptions of tutors' written responses. Assessment and Evaluation in Higher Education, 31(3), 379-394.

Weston-Green, K., \& Wallace, M. (2016). A method of providing engaging formative feedback to large cohort first-year physiology and anatomy students. Advances in Physiology Education, 40, 393-397. 